\title{
Schlachta, Astrid von, Gefahr oder Segen? Die Täufer in der politischen Kommunikation
}

\section{Mathilde Monge}

\section{OpenEdition}

\section{Journals}

Édition électronique

URL : http://journals.openedition.org/ifha/6665

DOI : $10.4000 /$ ifha.6665

ISSN : 2198-8943

\section{Éditeur}

IFRA - Institut franco-allemand (sciences historiques et sociales)

\section{Référence électronique}

Mathilde Monge, « Schlachta, Astrid von, Gefahr oder Segen? Die Täufer in der politischen Kommunikation », Revue de l'IFHA [En ligne], Date de recension, mis en ligne le 01 janvier 2011, consulté le 22 septembre 2020. URL : http://journals.openedition.org/ifha/6665; DOI : https://doi.org/10.4000/ifha 6665

Ce document a été généré automatiquement le 22 septembre 2020.

(C)IFHA 


\title{
Schlachta, Astrid von, Gefahr oder Segen? Die Täufer in der politischen Kommunikation
}

\author{
Mathilde Monge
}

1 Les anabaptistes, un danger ou une bénédiction ? La question que pose A.v.S., spécialiste des anabaptistes houttériens de Moravie, peut sembler hors de propos quand on pense à l'image que véhiculaient les anabaptistes dans la société d'Ancien Régime : la tentative d'instauration d'une nouvelle Jérusalem à Münster en 1534-1535 était pour les contemporains les « fruits » de ces hérétiques comparés en leur temps à des loups sauvages. D'un autre côté, Voltaire à Amsterdam admirait l'efficacité économique des mennonites, héritiers des anabaptistes du XVIIIe siècle. A.v.S. aborde cette apparente contradiction en étudiant du point de vue de la communication politique. Car les dissidents religieux, qui ne rentraient dans aucune « case " dans le Saint-Empire car affiliés à aucune confession de foi, étaient aussi un objet de communication. On cherchait à convaincre de leur caractère néfaste, alors qu'ils abordaient toutes les apparences d'une vie pieuse et austère ; mais parfois aussi on cherchait à justifier leur présence sur le territoire et les privilèges qu'on leur accordait. Les intéressés, qui se donnaient bien évidemment le nom de chrétiens, et qui se départageaient en parlant de mennonites, de Frères Suisses, de houttériens, participaient parfois eux aussi à ce discours.

2 Le livre est structuré en deux grandes parties. Après avoir brossé une utile " carte confessionnelle des déviants aux XVIIe et XVIIIe siècles ", A.v.S. traite d'abord d'une manière thématique des différents points abordés dans la communication politique autour des " anabaptistes ». Il s'agit d'abord de la place des confessions de foi « anabaptistes ", puis de la réception des discours de ces derniers. Ainsi, au XVIIe et XVIIIe siècle, la mémoire de la guerre des Paysans (1525) et du royaume anabaptiste de Münster est encore présente dans l'argumentaire utilisé contre eux. Cependant, un discours autour de la tolérance (tolerantia) apparaît à cette époque, et la notion de liberté de conscience qui s'impose pour les confessions « officielles » après les traités de 
Westphalie est utilisée à l'avantage des anabaptistes. Ces débats permettent aux anabaptistes de trouver une petite place dans certains États confessionnalisés.

Une deuxième partie est consacrée à la manière dont ces grands débats ont été mis en œuvre ou se sont cristallisés en conflits aigus dans différents territoires d'un SaintEmpire considéré de façon très large. A.v.S. commence en effet par traiter du rôle des anabaptistes dans la politique de la Confédération helvétique et aux Pays-Bas, qui sont en grande partie sortis de l'espace du Saint-Empire à cette époque. Sont ensuite traités le Palatinat électoral, Juliers-Berg, la Prusse et les territoires patrimoniaux des Habsbourg, autant de territoires qui pouvaient être des terres de refuge malgré l'opposition du Prince (le Palatinat) ou avec son autorisation (la Prusse) ou des terres d'où ils étaient chassés (les territoires des Habsbourg).

Le livre de A.v.S., écrit dans un style alerte, est une synthèse nouvelle et bienvenue sur un thème traité d'habitude (et par nécessité souvent) sous forme de monographies régionales et, à quelques exceptions près, jamais sous cet angle. L'auteur s'appuie à la fois sur une très large et très récente bibliographie, et sur des documents d'archives qui lui ont permis ponctuellement d'approfondir certains points que les historiens avaient trop peu traités. L'ouvrage, imposant, n'en est pas moins construit de façon commode et un index des lieux et des noms de personne permet de naviguer assez facilement dans le texte. On regrettera seulement que la « carte confessionnelle » ne soit pas accompagnée d'une ou deux vraies cartes.

$5 \quad$ Mathilde Monge (université de Strasbourg) 